\title{
Modeling systems thinking in action among higher education leaders with fuzzy multi-criteria decision making
}

\author{
Divya SHUKLA \\ St. Theresa International College, Bangkok, Thailand \\ divyashukla13@gmail.com
}

\begin{abstract}
The college and university systems are more complex and required persistent approach towards adoption and transformation. Highly vulnerable environment portrays the need to visualize the regular and strategic issues with the larger perspectives as a whole and develop a model which is more focused towards sustainability and reformation. The current study has attempted to conceptualize systems thinking in action model which consists of four stages of action cycle; diagnosis and analysis, modeling, intervention and review and lessons learned. This is attempting to evaluate the systems thinking among the educational leaders in higher education in Thailand through the fuzzy multi-criteria decision-making method. The study has found that leaders are adopting systems thinking in the moderate level, however, the first three stages are found less in practice and more in perceived importance. The study found that there is higher need of calling for collaborative, cooperative and participation of stakeholders' involvement. The study has further given managerial implications.
\end{abstract}

Keywords: systems thinking, higher education, fuzzy MCDM.

Please cite the article as follows Shukla, D. (2018), "Modeling systems thinking in action among higher education leaders with fuzzy multi-criteria decision making", Management \& Marketing. Challenges for the Knowledge Society, Vol. 13, No. 2, pp. 946-965, DOI: 10.2478/mmcks-2018-0015.

\section{Introduction}

Higher education is observing transformation all around the world. The pace of technological changes, innovative intervention in input and output of the process, globalization and multicultural workforce leading towards more complexities and fostering with varied first order change (within the systems) and Second order change (a reflection of the change in societies) (Ison, 1999). The global reformation with respect to persistent technological development and growing demand of innovation in industries necessitates skilled workforce who possess the competence to deal with environmental pressures and produce sustainable output with giving systems thinking based decision and policies. College and universities, therefore, play a pivotal role in making the learning more meaningful in terms of comprehensive sustainability. As these are complex adaptive systems (Debowski and Black, 2007), it should have the intention to move towards the advanced model of operation that focuses the dynamics of complex systems (Chillers 2000; Devis, Dent and Wharff, 2015). Robinson (2010) asserted that reformation is just not enough, as this simply improving the broken model, what we need, is not evolution but revolution. We have to make a shift from an industrial model which is manufacturing models of the standards, based on linearity, conformity and batching people to an agricultural model where humans are treated as an organic unit. They are facilitated with a condition where they flourish as human talents and it's retained right from the inner spirit. The challenges are forced to bring reformations in higher education. Hence what actually needed is transformation, as the 21st century is more globalized and interwoven with regular complexity, which 
imposes consistent pressure to adopt changes on educational leaders and higher education administrators. This often makes them functioned with event-based judgments which eventually turn into the more complex situation because approaches are reactive rather than pro-active. Leading in such contextual premise needs strong and wholesome thinking competence that produces high impact policies with the adoption of systems approaches. Those policies must be focusing on quality, efficiency and effectiveness with catering the need of competence among the professionals as an output of the universities learning process.

The prevailing challenges regulate the understanding of the holistic view of systems and leading towards restructuring, redesigning and re-engineering the strategic and functional level of the operations. Furst-Bowe (2011) strongly recommends the changes in Higher Education systems, right from the educational program, learning support services and administration. This necessitates the emergence of systems thinking while leading the academia as administrators, teachers, and researchers. Furst-Bowe (2011) asserted that when an organization is governed by systems thinking, work progress at faster and more efficient pace.

Thailand's Higher education scenario has witnessed several reformations to develop a sustainable education though, the phenomenal impact is still missing. Posai Busayamas (2016), asserted that Thailand's complex structure of higher education has lacked policy cohesion, this has suffered from intrinsic problems and crises, where there exist a low degree of collaboration between modern economic sector and higher education institutions, especially with Thai industries. Hence reformation is pivotal to compete on the global platform. The major initiatives that have taken are focusing on the reformation of the subsystems where teachers 'development, research initiatives, curriculum designing and Information Technology interfaces are minutely taken care. On the one hand, where labour market needs the high-end professional, but on the other hand the higher education still finds unable to fulfil the demand of the international workforce. This highly vulnerable environment portrays the need to visualize the problem with the larger perspectives as a whole and develop a model which is more focused towards sustainability and reformation. The model that consist the role brief of every stakeholder involved and interlinked especially with the role in the lead. These indicators are actually reflecting the need for systems thinking in the leadership approach as there are many changes forcing the leaders to think, react and adapt. However, a leader must understand the new adoption and its impact on the entire working on the organization as a systems. Furst-Bowe (2011) asserted that Leaders must recognize that making a change in one aspect of an institution will have impacts on many other areas of the institution. For example, the decision of increase in enrollment would lead the improvement in all the key processes and units, including marketing, recruitment, admission and financial aids which altogether must be aligned to achieve that goal. In the context of higher education where institutional learning is limited to one academic year as the periodical cycle of academic performance, the day to day decision impacts the long-term sustainability. Hence action-based model of systems thinking focusing in change cycle is required to conceptualize.

In higher education the systems perspective is needful to adopt as this involves establishing goals, assisting and allocating the resources, knowing key performance indicators and their respective driving urge, incorporating long-term perspective with a focus on sustainable green education. Where students are not just treated as a commercialized product rather they are nurtured and developed for the need of a sustainable word. Cabrera et al., (2017) asserted that there is a call for systems thinking 
in practical fields such as business, education and public health. It is particularly important to educators or organizational leaders who seek to develop systems thinking skills in students and employees.

Hence the paper attempts to explore the literature and conceptualize the systems thinking in action model applicable in Higher Education leadership. As the higher education need to observe the continuous improvement with adopting incremental changes in strategic, functional and operational level. This becomes a prominent question that how systems thinking can be evolved during change process so that improvement may focus on holistic growth and sustainability of the systems. This study is, therefore, attempting to postulate systems thinking in action model and evaluating the systems thinking criteria among the educational leaders in higher education in Thailand through the fuzzy multi-criteria decision-making method.

The present paper has arranged in structural order where first literature review on the systems thinking has been undertaken followed by gap identification and conceptualization of model. Second, the method has been described with the fuzzy application of data analysis. Third the results are discussed with empirical findings and fourth implication of research in practical and theoretical perspective have been given along with the future scope of the investigation.

\section{Literature review}

\section{Evolution of systems thinking}

The root of systems thinking emerged with the evolution of General Evolution Systems Theory. In relation to study of perception, general evolution theory provides a conceptual foundation for theories and tenets of evolutionary ethics (Lastzlo and Kreepar, 1998). General Evolution Systems Theory covers the theoretical conceptualization of systems ideas and their interrelations whereas social systems design helps to understand these ideas in real work environment more vividly. Checkland (2000) represents this classification in 'Hard' and 'Soft" systems approach where hard represents engineering and mechanical image, and soft depicts behavioural and psychological underpinning. He claims a hard system is easy to predict and understand whereas soft systems approaches are complex and unclear. As the level of individual psyche consist multiple processes of perception, interpretation, representation, and communication (Lastzlo and Kreeper, 1998). The concept then proceeded to relate the thinking with designing open systems and birth of evolutionary systems design occurred that seeks to develop evolutionary competence. Lastzlo and Kreeper (1998) define evolutionary competence that refers to the state of selfactualization (of individual and group) that is marked by the mastery of the knowledge, the abilities, the attitudes and the values required for co-evolutionary actions and therefore for the pursuit of the sustainable mode of being. The literature has supported the several prominent bases of systems theory (Bertalanffy, 1968), Socio-technical systems theory (Hill 1971; Charms, 1976), living systems theory (Miller 1978), Soft systems methodology (Checkland, 1981) and social systems sciences (Ackoff, 1974; Mitroff and Mason,1981). All the above theories are meaningful with their distinguished application in operational research, systems engineering, and management science and so on. These altogether reflect the several components of the systems thinking which give a base for defining the traits and competence of the systems thinker. Assessing the systems thinking is a challenging task as the literature has not furnished any valid assessment tool. This reflects the need for a thematic review on what are the systems thinker do in their respective practices, what traits and behavior they possess which 
speaks about their skills and competence. Literature has furnished a distinguished representation of the systems thinking in the different field of investigations such as public health, engineering, and education. The present literature review is attempting to study the systems thinking in practice approach where 'how systems thinkers must act in higher education scenario?' would be taken as a question of the investigation.

\section{Systems thinking traits and behavior}

The traits of systems thinking have been studied in a variety of settings (Davidz, H. L., \& Nightingale, D. J. (2008); Hooper and Stave, 2007; Frank M, 2010). Gharaajedagi J. (1999) defines the systems thinking traits on simplifying, complexity, manage interdependency and understand the choice. Richmond, (1993) claims the seven critical skills that are prominent in systems thinker, first dynamic thinking, described as the ability to see and deduce behaviour patterns rather them focusing on and seeking to predict events. Second; closed-loop thinking which says the ability to look to the loop themselves (i.e. the circular cause-effect relations) as being responsible for generating the behaviour patterns exhibited by a system. Third skills generic thinking i.e. ability to apprehend the similarities in the underlying feedback loop relations that generate cycles. Fourth skill is structural thinking which requires people to think of a unit of measure or dimensions. The distinction between stock and flow is emphasized here. Fifth skill is operational thinking which is closely linked to structural thinking. Operational thinking means thinking in terms of how things really work. Sixth skill is continuum thinking involves working with simulation models that have been built using a continuum, as opposed to discrete modeling approach. Seventh skill is scientific thinking which encompasses rigorous hypothesis testing which emphasizes on quantification of measurement. People thinking scientifically modify only one thing at a time and holds all as constant (Davidz, at al. 2008). Moore , Dolansky, Singh, Palmieri, Alemi (2010) has given one criteria for system thinker i.e. interconnection of factors which means patterns of relationships. Hooper and Stave (2007), has given seven criteria recognizing interconnections, identifying feedback, understanding dynamic behavior, different types of flows and variables, using conceptual models, creating simulation models and testing policies. He has given three levels of systems thinking in his continuum basic, intermediate and advanced basic level of recognizing interconnection, identifying feedback, understanding of dynamic behavior, the intermediate level is consisting of differentiating types of variables and flows and using conceptual model. The last defined is creating simulation models of testing policies. Davidz (2006) conceptualize eighteen traits, he said that a systems thinker thinks broadly with big picture view, they are creative, out of the box not detailed focused, holds multiple perspectives, they possess curiosity, inquisitive, analytical and logical, strong interpersonal skills, listening, communication, self-confidence, disciplined, structured, methodological, organized, abstract thinking, initiative, wide and varied background, ongoing extrovert, tolerance for uncertainty, open minded. Frank (2010) reflected the behavior traits of the system thinker. According to the author the understanding of the whole systems, understanding of inter-connection, thinking creatively, understanding systems without getting stuck on details, tolerance for ambiguity, understanding systems in multiple perspectives, curious ask good questions, analytical, create build and use simulations, good communication and interpersonal skills, have self-confidence and disciplined. Behl and Ferreira (2014) defines the three elements of systems thinking first as understanding the whole systems means comprehending the systems holistically, taking into consideration all its elements, 
subsystems, assemblies and component. Second understanding interconnection means having the knowledge and ability to understand relationship and interdependencies between systems elements at the hierarchical level of systems, along with the result of interrelations between systems elements. Third, consider and use of multiple perspectives means understanding the systems from diverse and several points of view. Kordova \& Frank (2015) has propounded the systems thinking of engineering professionals with fourth layer approach right from thinking assessment to its decomposing to successful systems thinkers. The findings of the study has classified System Thinking into competencies, abilities, traits and dealing with multidisciplinary knowledge and experience. However, researcher has looked upon systems thinking competencies in educational context reflecting the commonalities in regards to the traits and behavior. Arnold and Wade (2015) has define the systems thinking in eight dimensions which include; recognizing interconnection, identifying and understanding feedbacks, understanding systems structure, differentiating types of stocks, flaws and variables; identifying and understanding non-linear relationship, understanding of dynamic behavior, reducing complexity by modeling systems conceptually, understanding different scale. Peggy and Carl (2017) asserted that the systems thinking methodology is concerned with developing and testing operational explanation of organizational behavior and as such requires an understanding of the "whole" through the relationship between "organizational pieces".

\section{Systems thinking in higher educational context}

In the context of higher education scenario, literature have multiple pieces of evidence in western educational institutions where systems thinking has been widely applied in school and community college. Considering the scenario in higher education and its several components such as students, teachers, parents, administration, courses, curriculum, legislation, funding, and buildings or infrastructural support together with psychological capitals i.e. personalities, perceptions, ambitions, competitions, cultural and spiritual belief and its further connectivity to the institutional labor market contribution and associating community serving. Entire picture has complexity with a sense of interlinked functionality (Despress, B.R. 2004). Despress (2004) said that education leaders need to understand more than behavioural incidents and institutional operations. Ayer (2002) has studied systems thinking in educational process with flexible and flattened organizational structures, multi-directional communication, and interdependency of network collaboration. Levin et al. (2010) promoting partnership aligning support and resources, adapting to changing contexts, shifting structures to recognize faculty contribution as an important component of systems thinking in higher education. In support to this Jenkins (2007) explains that systems thinking traits for leaders who strengthen alignments ensure coordination and integration of service across campus, faculty, staff, and administrators which are elements of systems thinking approach. However, the dependencies on discovering needs of stakeholders with designing change plan suitable to their needs have also included in the systems thinking paradigm (Clark and Lehaney, 2000). Huston et al. (2008) proposed similar characteristics such as discovering values and concerns of stakeholders, mapping boundaries, interdependencies and structural framework for interventions. He found that visually mapped boundaries and academic department interdependencies with the structural approach of intervention that are aligned with values, altogether may lead towards quality improvements and eventually success. Devis, Dent, and Wharff (2015) asserted that educational leaders must comprise three valuable practices of systems 
thinking; first a discovery which defines as exploring and justifying boundaries for the inclusion of stakeholders and issues, uncover values and assumptions of stakeholders through participatory practices and identifying marginalized groups. Second; framing that explains as mapping pattern of behaviour and model feedback loops, diagram relationship and identifying points of leverage, structural interventions, and design framework for change. Third and last practice is to engage participants of all stakeholders, promote coordination; collaboration and coordination of network align support and resources. However, the system thinking becomes more evident with improvement perspectives where leaders conceptualize the context and make decisions on the basis of the systems improvement. Hence, this leads the conceptualization of the systems thinking in action perspective.

\section{Conceptual gap identified}

The extensive review reveals that systems thinking has been discussed in the policy, competence or trait perspective but in action has observed with less attention. There is not any literature found where thinking is assessed in action perspective where change cycle has taken into consideration, therefore, the current study conceptualizes the systems thinking in action perspective and contributes to the available literature with postulating and validating the systems thinking in action model. The present study also presents novelty with respect to geographical context, there is no such study observed in the context of Thailand where systems thinking among the practitioners in higher education has been evaluated.

\section{Systems thinking in action}

The need of persistent improvement in the strategic, functional and operation level present a situation to observe the plan, do, check, and act process in every strategic decision that leader make for the benefit of the institution. To gain the improvement and produce graduates with meeting the demand of the industry and at the same time justifying the stakeholder's requirement, compels to observe the change in every step of the change cycle, and make a special effort to experience the success in each step of the cycle. The systems thinking in action was given by Peter Senge in 1995 however using the logic model and theory of change incorporating action research model (Robbins 2006), identical to Lewin's (1946) baseline model, the four phases of action cycle is being conceptualized here in regards to systems thinking. Whenever the Institute strives for change, has to look upon the criteria associated to each cycle. Figure-1 depicts the pictorial presentation of the same. The respective criteria are discussed as follows:

Step First; Diagnosis and analysis phase; This phase includes the in-depth investigation on the stakeholder's needs and demands with the resourceful utilization of data analysis in order to identify the improvement in the process and delivery outcome of the university; which has five criteria depicted below:

1. Vision and mission implementation in the process; this reveals the thinking that leaders relate each result and procedural gains or anomalies with the vision and mission of the institutions while making a judgment.

2. Uncovering the stakeholders' values and opinion (Gregory and Midgley, 2000; Midgley, Memlo and Brown, 1998; Caputo, F. 2016.); Leaders support in making participatory meetings for gaining the understanding of identified stakeholders involved in program learning and process execution, uncovering the needs that are 
unidentified and justifying the wholesome progress.

3. Conducting Surveys; In order to gain the complete feedback and knowing the performances in every system, the institution's heads intend to conduct the timely survey and know the possible improvement.

4. Use of data analytics in situation analysis: to obtain the clear picture on the issues, leaders are dependent to the data analytics and their contribution in overall decision making, hence appropriate use of the tool and timely application must be taken into account while diagnosing and analyzing the performance outcome or problem.

5. Understanding on the inter-linkage between soft and hard systems and level of interdependencies. (Temel, 2005); This reveals that leaders have the input of interdependencies between soft and hard systems of the organizations, he must diagnose the deviation in the process keeping in mind the inter-connectedness of subsystems and systems.

Second; Modeling phase; This phase includes the mapping of the systems with the behavioural pattern observed in individual, group and organizational level. This has;

1. Mapping systems and behavioural pattern (Temel, 2005) observing behavioural pattern prevailing in each level of the organization may enhance the chances of clear understanding on the deviation or the process flow and therefore contribute better for making the best decision.

2. Problems with visual mapping of the systems inter-linkage (Kapsali,2011); Making clear boundaries between academic and non-academic departments and knowing their interdependencies while making policies or decision.

3. Conceptual modeling of the cognitive paradigm of stakeholder's (Cordoba and Midgley, 2008) involved perspectives that leader tend to know the views and opinion of diverse stakeholders and worldviews.

4. Modeling systems change and improvement (Houston, Robertson and Prebble, 2008) depicts that leader has a structural approach to view each system and its component, knowing the 'problem map'.

5. Developing framework for initiating change (Clarke and Lehaney, 2000): Reflects that leader develops the structural intervention through modeling change initiatives for improving systems or its component.

Third; Intervention and action phase; this phase included making an action or initiating change by aligning each component of the systems, this includes;

1. Making action of initiating change; this depicts that leaders contribute to making the change happen through active participation.

2. Aligning support and systems (Levin et al., 2010) is representing aligning support and resources with respect to the change initiative and long term and short-term goal of the system.

3. Promoting Collaboration among stakeholders (Jenkins, 2007) is promoting collaboration among faculty members, staff, administrators or industry practitioners, community leaders etc.

4. Directing and motivating the performance towards goals: Persistent motivation and direction towards goals attainment of staff and faculty members.

5. Persistent feedback loop checking and applying control on deviations (Wolstenholme, 1993) this reveals that leaders keep a watch on feedback loop coming out of each stakeholder of the university. 


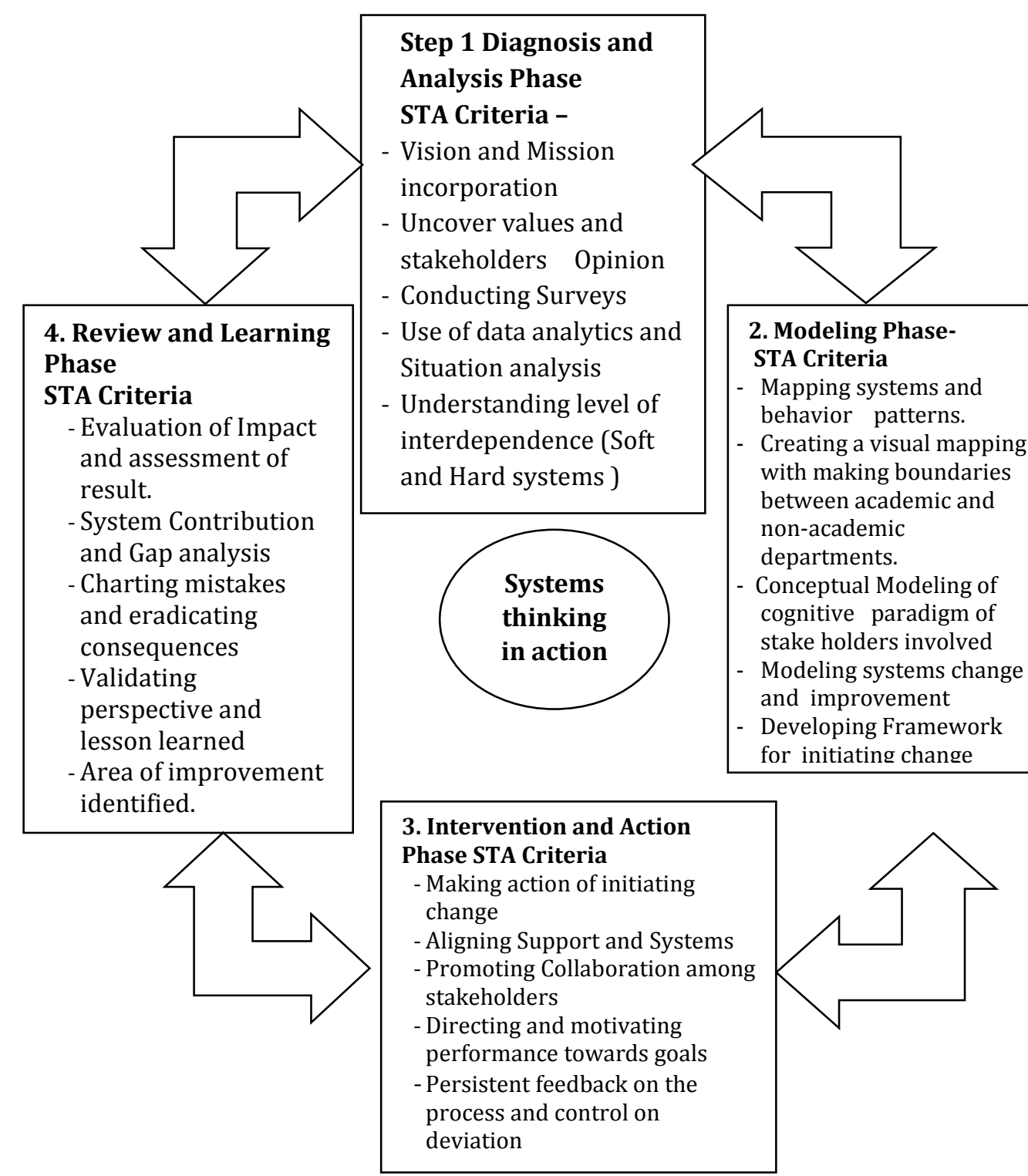

Figure 1. Systems thinking in action model (STA)

Source; Author's own conceptualization.

Fourth and the last phase is Review and learning phase; This stage reveals the evaluation aspect where the success and failures of the operation plan or adopted changes comes into focus. This includes;

1. Evaluating impact and assessment of results; this reflects the Leader's attention towards the impact assessment of the undertaken change plan or policy.

2. Systems contribution and gap analysis; this reflects on gap analysis and contribution of change plan or development initiative (positive or negative) on overall development of the organization.

3. Charting mistakes and eradicating consequences; Does leader do write or record the mistakes and try to take those into consideration while executing the next year planning and assessment?

4. Validating perspective and lessosn learned; this reflects that leaders validate their thought process with the consequences and result obtained and make their understanding of the lesson learned. 
5. Identification of the area of improvement: the assessment of the key area of improvement that has shown unrealized goals or has failed to obtain the desired outcome.

\section{Methodology}

The study has taken the empirical investigation to access systems thinking with incorporating multi decision-making criteria a Fuzzy-based approach to investigation. Singh Kushwaha and Kumar (2009) recommended the use of fuzzy logic in the study of human behaviour as this ensure precision and reduce uncertainty.

The design of the study has observed following steps (Figure-2); First; the conceptualization of research instrument has been done with developing criteria on systems thinking in action perspective, Second; the data has been collected, third: the quantification of the obtained data which has been processed with fuzzification of the score of twenty criteria for performance level and perceived importance level, the respective weight score with their inferences drawn after the analysis. The defuzzification is applied then after to know the precise status of systems thinking in action. Fourth; has facilitated the interpretation and understanding of the gap between performance level (STA in practice) and Importance level.

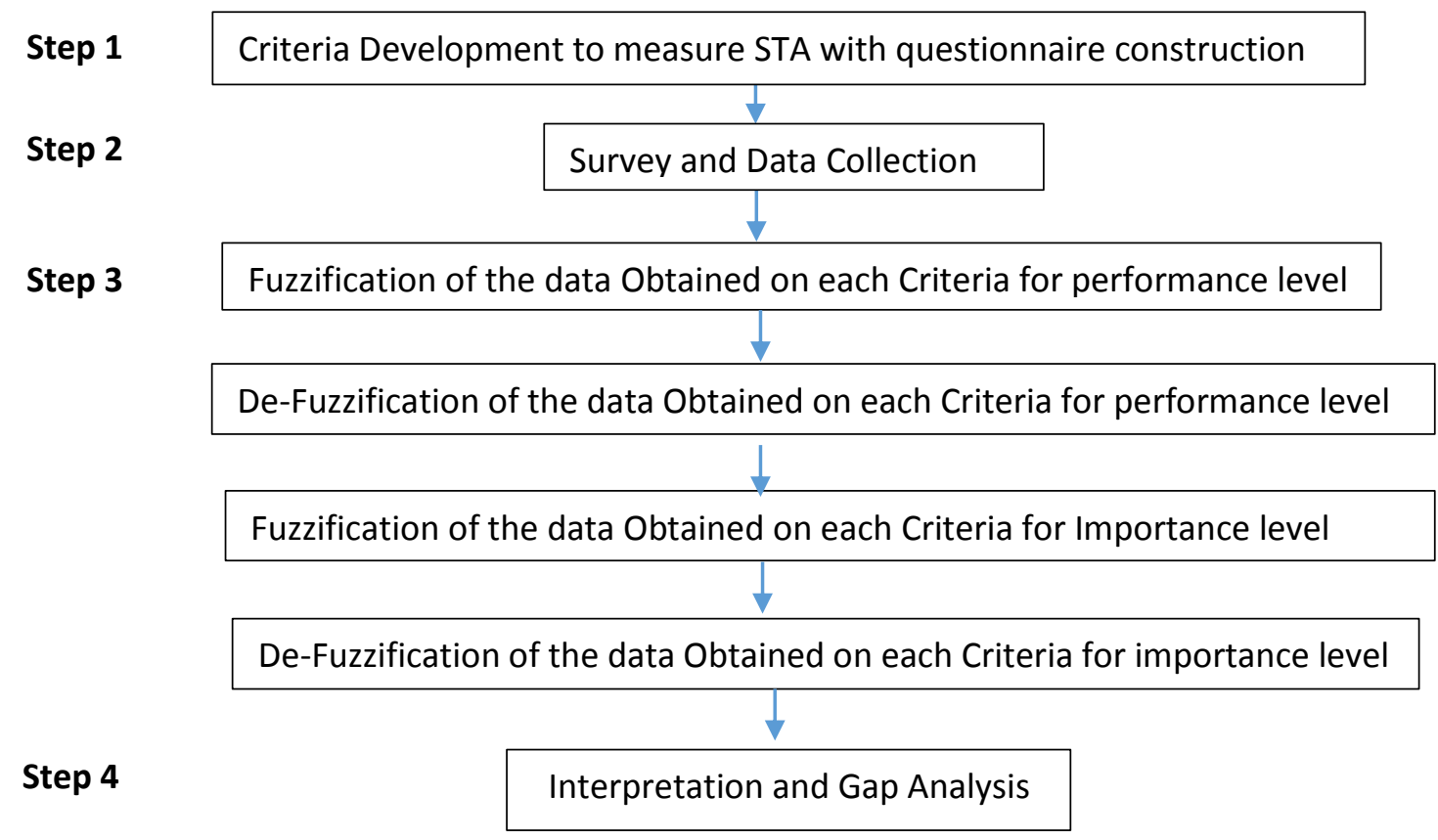

Figure 2: Research Process

\section{Sample design}

Source: Author's own conceptualization.

The study has taken a purposive and convenient sampling. The total 250 individuals in decision making role such as departmental heads, deans, assistant deans, vicepresidents and presidents who are employed with higher educational institute and university in Bangkok City have been approached to participate in the survey. The data have collected through online survey and direct participation. 199 completed surveys have been utilized for empirical investigation representing $79.6 \%$ of the response rate.

\section{Instrument description}

Based on the four phases of the action model as cited above with twenty items used for evaluating criteria of systems thinking in action (Figure 2), the three section of the 
instrument are designed; measuring the performance level, importance level and demographic profile consecutively. The performance level has assessed by converting criteria into the action statement whereas perceived importance level has assessed through similar items mentioned in the model. The five-point Likert scale has utilized for performance level where 5 is rated as strongly agree and 1 as agree. The scale utilized for importance level is 5 as very important and 1 as not important. For the comprehensive analysis of the scale validity and reliability, the obtained statistical score has been furnished in Table 1. This consist the Cronbach alpha, KMO values and Bartlett test of Sphercity. The analysis reflects that the scale is reliable and valid as all the obtained statistical values are in acceptable range. The entire scale has scored .93 as the alpha score for the reliability and KMO as .85. Hutcheson and Sofroniou (1999) recommended that values between 0.8 and 0.9 for KMO are superb which reflects the appropriateness of data adequacy. Bartlett's Test of Sphercity also found significant at 0.05 level which depicts that data matrix is not an identity matrix. The obtained reliability and validity score reflect that the source carries adequate reliability of the obtained data.

Table 1. Reliability and Validity scores of the scale

\begin{tabular}{|l|l|l|l|l|l|l|}
\hline Dimensions & $\begin{array}{l}\text { Number of } \\
\text { Items }\end{array}$ & $\begin{array}{l}\text { Cronbach's } \\
\text { Alpha }\end{array}$ & $\begin{array}{l}\text { KMO } \\
\text { Values }\end{array}$ & $\begin{array}{l}\text { Chi- } \\
\text { Square }\end{array}$ & Dof & Sig \\
\hline Entire Scale & 20 & .93 & .85 & 2927.47 & 190 & .00 \\
\hline Diagnosis/Analysis & 05 & .84 & .78 & 371.43 & 10 & .00 \\
\hline Modeling & 05 & .85 & .80 & 466.91 & 10 & .00 \\
\hline Intervention/Action & 05 & .76 & .69 & 327.08 & 10 & .00 \\
\hline $\begin{array}{l}\text { Review and Lesson } \\
\text { Learned }\end{array}$ & 05 & .85 & .85 & 445.50 & 10 & .00 \\
\hline
\end{tabular}

$\mathrm{P}<0.05, \mathrm{KMO}=$ Keiser Meyer-Olkin, DOf $=$ Degree of Freedom

Source: Primary Data Analysis.

\section{Fuzzy conceptualization and analysis}

Fuzzy Set Theory has been incorporated to furnish the findings. Systems thinking model scales the rating for importance and measurement of the respective criteria. Often the rating is done on the basis of the crisp numerical value which may often result in vague and imprecise results (Pandey, 2016). Since the measurement of systems thinking in action encompasses intrinsic complexity, hence Fuzzy Set Theory renders an effective approach to gauge it by using interval-based linguistic variable.

The concept of the fuzzy set was founded by Zadeh (1973) with the purpose to measure the human preference more pragmatically by the help of the linguistic term (Pandey, 2016). Fuzzy Set Theory renders a strict mathematical framework in which imprecise conceptual phenomenon can be measured precisely (Zimmermann, 2001; Zadeh, 1973; Bellman \& Zadeh, 1970; Zadeh L. , 1975; Hwang \& Yoon, 1981; Liang \& Wang, 1991; Hsu \& Chen, 1997; Chiadamrong, 1999; Chien \& Tsaia, 2000; Chen, 2000; Enrique, 2004; Pandey et al., 2018; Garg, 2017).

A fuzzy set is a set without a crisp, clearly defined boundary and contains elements with only a partial degree of membership (MathWorks, 2012). MathWorks (2012) defines a membership function (MF) as a curve that explains how each point in the input space is mapped to a membership value (or degree of membership) between 0 and 1 . The concepts of a linguistic variable can be quantified by fuzzy numbers using suitable membership functions. Various types of membership functions such as 
triangular, trapezoid, linear, sigmoidal, pie type and Gaussian are utilized and the most widely applied membership function is a triangular membership function (Pandey, 2016). Triangular fuzzy numbers can be defined as (l1, $\mathrm{m} 1, \mathrm{u} 1)$ where $l 1 \leq \mathrm{m} 1 \leq \mathrm{u} 1$ and it can be represented in terms of membership functions (Jia, Govindan, Choi, \& Rajendran, 2015).

The study undertakes linguistic variables to assess the systems thinking in action criteria. Table 2 and 3 represents the linguistic variables of the performance level and perceived importance level of criteria where the crisp value rating has been represented as Triangular Fuzzy Number (TFN).

Table 2. Linguistic Variable for systems thinking criteria in action

\begin{tabular}{|ll|}
\hline Strongly disagree & $(0.0,1.0,2.0)$ \\
\hline Disagree & $(1.0,2.0,3.0)$ \\
\hline Neutral & $(2.0,3.0,4.0)$ \\
\hline Agree & $(3.0,4.0,5.0)$ \\
\hline Strongly Agree & $(4.0,4.5 .5 .0)$ \\
\hline
\end{tabular}

Source: Mathworks.( 2012) and Pandey (2016).

Table 3. Linguistic Variable for systems thinking criteria in perceived importance

\begin{tabular}{|cc|}
\hline Not Important & $(0.0,1.0,2.0)$ \\
\hline Slightly Important & $(1.0,2.0,3.0)$ \\
\hline Moderately Important & $(2.0,3.0,4.0)$ \\
\hline Important & $(3.0,4.0,5.0)$ \\
\hline Very Important & $(4.0,4.5 .5 .0)$ \\
\hline
\end{tabular}

Source: Mathworks (2012) and Pandey (2016).

The graded mean integration representation has been applied to transform the TFN (Triangular Fuzzy Number) for data analysis. The method was conceptualized by Chen and Hsieh (1998) which is based on the integral value graded mean by fuzzifying generalized fuzzy numbers. The method has been further has been developed with canonical representation of multiplication of two triangular fuzzy numbers by graded multiple integration representation methods. Chau (2007) added a variation with inverse function arithmetic representation for multiplication of multiple trapezoidal fuzzy numbers. Chien-Chang (2012) has developed the approach where criteria performance and weight scores were transformed into a triangular fuzzy number. In line with the methodology of Pandey (2016) and Chien-Chang (2012), this paper undertakes Fuzzy MCDM (Multiple Criteria Decision Making) Model for assessing the systems thinking in action criteria using a canonical representation of TFN. The basic arithmetic on TFN has been explained as if $\mathrm{X} 1=\mathrm{a} 1, \mathrm{~b} 1, \mathrm{c} 1$ and $\mathrm{X} 2=\mathrm{a} 2, \mathrm{~b} 2, \mathrm{c} 2$ then arithmetic multiplication may be indicated by equation 1 .

$\mathrm{X} 1 \times \mathrm{X} 2=(\mathrm{a} 1, \mathrm{~b} 1, \mathrm{c} 1) \times(\mathrm{a} 2, \mathrm{~b} 2, \mathrm{c} 2)=(\mathrm{a} 1 \mathrm{a} 2, \mathrm{~b} 1 \mathrm{~b} 2, \mathrm{c} 1 \mathrm{c} 2)$ equation 1

By employing graded mean integration a TFN value is transformed for data analysis as depicted in equation 2. The above transformation is done for both importance and performance rating.

$\mathrm{P}(\mathrm{Y} 1)=\frac{1}{6}(\mathrm{c} 1+4 \mathrm{a} 1+\mathrm{b} 1)$ equation 2

The criteria importance score on systems thinking $(\mathrm{i}=1,2, \ldots \ldots \ldots \ldots \mathrm{w})$, which is rated with nth leaders $(n=1,2, \ldots \ldots . . n)$ are denoted by TFN's respectively and are fuzzified 
with incorporating graded means method indicated by equation 2 . The fuzzified importance score on systems thinking criteria is represented as $W_{\text {in }}$ which indicates the importance score of $i^{\text {th }}$ criteria for $\mathrm{n}^{\text {th }}$ leader. The defuzzification has been incorporated to gauge the importance level of each criterion using equation 3.

AWik $=\frac{\sum_{n=1}^{N} \text { win }}{\sum_{i=1}^{I} \sum_{n=1}^{N} \text { win }}$ equation 3

The average score of the performance on systems thinking is calculated on the basis of equation 4 which is based on inverse function arithmetic representation method. This has taken the scores of two TFN of Performance and Importance of systems thinking criteria as the aggregate score for the entire population.

$\mathrm{TS}_{\mathrm{k}}=\frac{1}{N} \sum_{i=1}^{I} \sum_{n=1}^{N} A W i k \otimes S i k n$ equation 4 


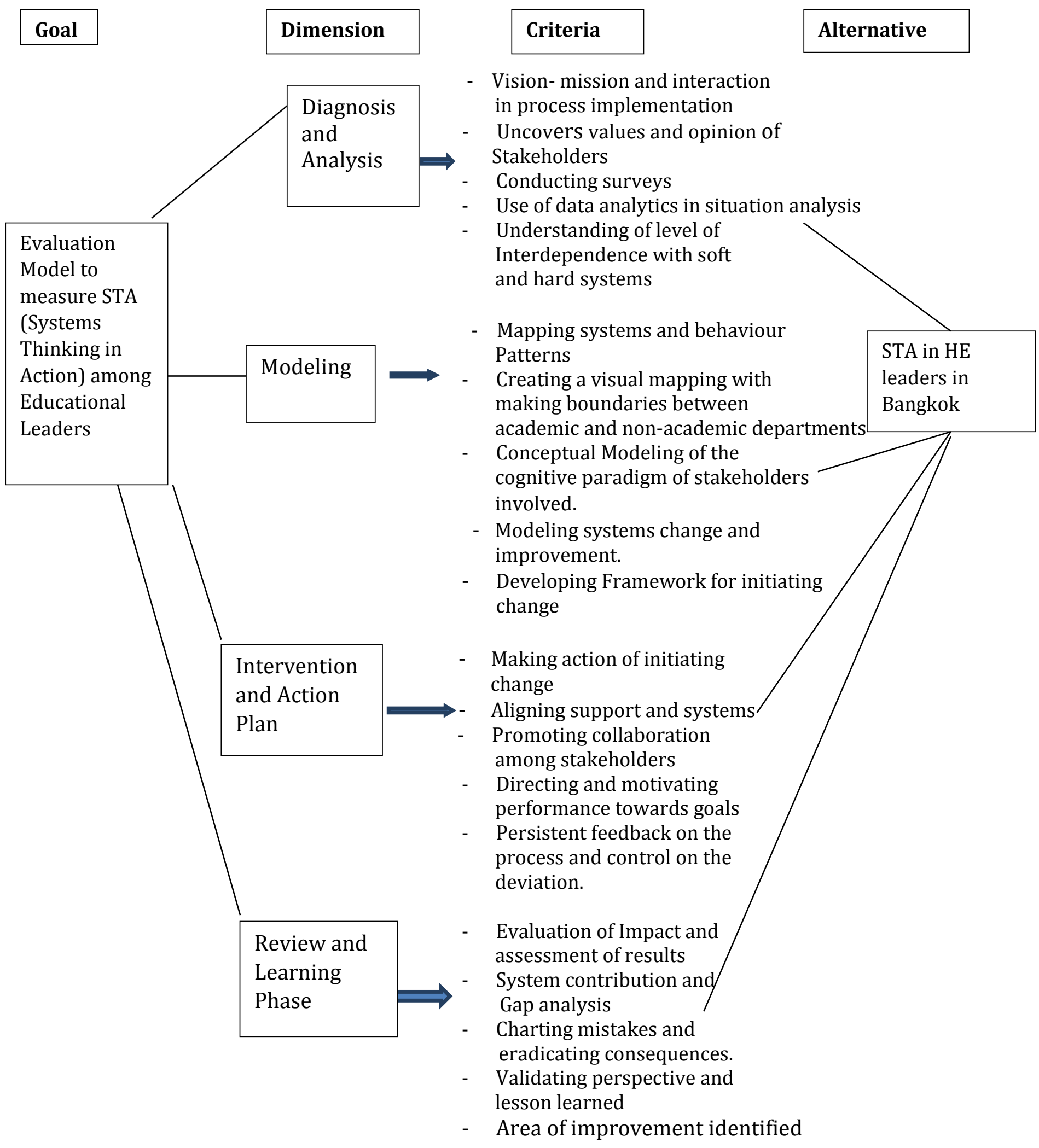

Figure 2. Hierarchical analysis structure for evaluation of the phases of systems thinking in action

Source: Current Research Model. 


\section{Findings}

The study observed that overall systems thinking in action among the higher education leaders are in the satisfactory level, as the obtained score is 3.58 which reflects the aggregate average score of practising systems thinking in action. The scores on the perceived level of Importance and performance level i.e. ST in practice for the observed criteria have been given in Table 4. The statistical observation reveals that for the first phase; diagnosis and analysis; leaders are incorporating vision and mission in the process, they are organizing meetings to understand the values and opinion of stakeholders. The performance level and importance level have been found relatively similar for all three dimensions respectively 3.50, 3.54, 3.87, and 3.01, 3.02, 3.87. The use of data analysis in situation and level of interdependencies is required to be considered for improvement as the actual performance score in less than perceived importance level score $(3.63,4.28,3.79$, and 4.33$)$. The present finding supports the claims of Khalkhali Ali et al. (2012) inferring that systems thinking provides the opportunity for managers to organize their organizational subsystems to reach the goals and warranty the effectiveness of organizational collection. For the second Phase; modeling leaders are found less in mapping the systems pattern and behavior patterns as the statistically observed value is 3.76 which is less then perceived importance score (4.36). The status for creating a visual mapping with making boundaries of the academic and non-academic department has found at the satisfactory level as the observed score is 3.47 for action and 3.51 for level of importance, reporting minimum gap. The mapping of the cognitive paradigm of all the stakeholders involved in the process has reported with moderate status (3.52) which has observed less from importance level i.e.3.98. For adopting change and modeling systems change and improvement the gap has been observed more as the observed statistics for actual performance (3.66) is less than perceived importance level (3.99). The finding of the current research partially support the study of Debowski \& Blake, (2007), who adopted complex adaptive systems theory to explore an integrated model of the collective capacity building, he found that leaders must demonstrate the collective participation in learning and development with community stakeholders. However, leaders are found engaged in developing a framework for initiating change at the moderate level of observance (3.40) that reflect the need to work on the all four criteria observed for modeling.

The Third dimension that depicts the modeling into action with taking intervention and making action plan has observed a profound gap. 'Aligning support and systems' and 'directing and motivating performance' towards the goals are the two criteria that have found with an observable gap between performance or importance level representing $(3.77<4.27)$ and $(3.58<4.28)$ score. The study also reported that the persistent feedback of the process and control of deviation is less than the expectation for the fourth dimension review and lesson. The gap has also observed for validating perspectives and lesson learned which reflects that the experiences are required to be considered in regards to the prevailing situation and may be taken as a lesson for the organizational learning.

Overall observation has revealed that phases of diagnosis and analysis, modeling and intervention and action plan are found less in practice and more in importance level, on the contrary, the review and lessons learned are more in practice tnan in importance level. The leaders are found to be practising systems thinking but not in the higher level of practice, which is needed to handle the complex structure of Higher education. 
Table 4. Importance and Performance score on Observed Criteria

\begin{tabular}{|c|c|c|c|}
\hline Dimensions & Criteria & $\begin{array}{l}\text { Performance } \\
\text { on STA }\end{array}$ & $\begin{array}{l}\text { Importance } \\
\text { of STA }\end{array}$ \\
\hline \multirow{5}{*}{$\begin{array}{l}\text { Diagnosis and } \\
\text { Analysis }\end{array}$} & $\begin{array}{l}\text { Vision- mission and interaction in } \\
\text { process implementation. }\end{array}$ & 3.50 & 3.01 \\
\hline & $\begin{array}{l}\text { Uncovering values and opinion of } \\
\text { stakeholders }\end{array}$ & 3.54 & 3.02 \\
\hline & Conducting surveys & 3.87 & 3.87 \\
\hline & $\begin{array}{l}\text { Use of data analytics in situation } \\
\text { analysis }\end{array}$ & 3.63 & 4.28 \\
\hline & $\begin{array}{l}\text { Understanding of level of } \\
\text { interdependence between soft and } \\
\text { hard systems. }\end{array}$ & 3.79 & 4.33 \\
\hline \multirow{5}{*}{ Modeling } & $\begin{array}{l}\text { Mapping systems and behaviour } \\
\text { patterns }\end{array}$ & 3.76 & 4.36 \\
\hline & $\begin{array}{l}\text { Creating a visual mapping with } \\
\text { making boundaries between academic } \\
\text { and non-academic departments. }\end{array}$ & 3.47 & 3.51 \\
\hline & $\begin{array}{l}\text { Conceptual Modeling of the cognitive } \\
\text { paradigm of stakeholders involved. }\end{array}$ & 3.52 & 3.98 \\
\hline & $\begin{array}{l}\text { Modeling systems change and } \\
\text { improvement. }\end{array}$ & 3.66 & 3.99 \\
\hline & $\begin{array}{l}\text { Developing Framework for initiating } \\
\text { change }\end{array}$ & 3.40 & 3.34 \\
\hline \multirow{5}{*}{$\begin{array}{l}\text { Intervention and } \\
\text { Action Plan }\end{array}$} & Making action of initiating change & 3.57 & 4.17 \\
\hline & Aligning support and systems & 3.77 & 4.24 \\
\hline & $\begin{array}{lll}\begin{array}{l}\text { Promoting } \\
\text { stakeholder }\end{array} & \text { collaboration } & \text { among } \\
\end{array}$ & 3.50 & 3.86 \\
\hline & $\begin{array}{l}\text { Directing and motivating performance } \\
\text { towards goals }\end{array}$ & 3.58 & 4.28 \\
\hline & $\begin{array}{l}\text { Persistent feedback on the process } \\
\text { and control of the deviation }\end{array}$ & 3.30 & 3.38 \\
\hline \multirow{5}{*}{$\begin{array}{l}\text { Review and Lesson } \\
\text { Learned }\end{array}$} & $\begin{array}{l}\text { Evaluation of Impact and assessment } \\
\text { of results }\end{array}$ & 3.62 & 3.73 \\
\hline & System contribution and gap analysis & 3.59 & 3.07 \\
\hline & $\begin{array}{l}\text { Charting mistakes and eradicating } \\
\text { consequences. }\end{array}$ & 3.12 & 3.23 \\
\hline & $\begin{array}{l}\text { Validating perspective and lesson } \\
\text { learned. }\end{array}$ & 3.71 & 4.18 \\
\hline & Area of improvement identified & 3.73 & 3.27 \\
\hline
\end{tabular}

\section{Conclusion and discussion}

The study attempted to measure the systems thinking in action with special reference to the educational leaders in Thailand and found that education leaders are moderately using the systems thinking's in action. However, meeting the challenges of higher education the leaders need to improve the systems thinking. Skarzauskiene (2009) claims that systems thinking competence and retention of cognitive abilities can significantly improve both efficiencies of leadership and organization. As asserted by Mononen (2017) that systems thinking is a holistic approach that needs a change of worldview or paradigm shift to be used in an appropriate sense. Instead of outer 
systems, inner systems such as design thinking, perception and cognition is very important to apply the systems thinking in practice (Mononen, 2017). As the study reveals that leaders need to pay attention to first three stages of the systems thinking in action model. They are required to give due focus on data analysis driven decisions where interdependence of hard systems (physical and material) and soft systems (behavioural and psychological prevailing in systems) is taken well care off. Mapping the behaviour pattern with modelling the cognitive paradigm or prevailing thought patterns of stakeholders such as students, teachers, community leaders and employers is very important while making change decision or initiating existing improvement plan. Directing and motivating performance towards goals seems another area of improvement that leads towards holistic development and success. Apart from the empirical findings, the study is contributing with the conceptual foundation of systems thinking in action plan where four distinguished stages of action have been conceptualized to assess the leaders' systems thinking in action with special focus on higher education scenario.

\section{Implications of the research}

The current study contributes the managerial implication with regard to the prioritized criteria to implement systems thinking in action in the decision making of leaders of higher education especially in Thailand. As the finding reveals the scenario requires the higher need of calling for collaborative, cooperative and participatory leadership where stakeholders are active and focused, participative, executive and evaluative on sustainability (Caputo, F. 2016, Devis, Dent and Wharff, 2015). This strongly propagates the need of stakeholders involvement, the present finding goes along with the McLean (2005) who claims that it is important to build stakeholders ownership, a respectful relationship between academics and professionals, collaboration and group ownership of change, a valuing of internal expertise and the avoidance of top-down approach. The present study would help the leaders to know the area of improvement in given model for making higher education more sustainable and effective. The criteria given in tool may be taken as input in pre-selection test or career development of academic leaders. This would assist the leaders to understand their role and perform the change cycle for larger improvement as the universities are in need to adopt the systems thinking in larger strategic reforms to respond external expectation and pressures, while making incremental changes in internal academic and admin structures (Beer and Nohria, 2000; Debowski and Blake, 2007) .

The theoretical implications facilitate the research tool to the researcher and academicians who are intending to study the systems thinking in strategic level especially with relevance to the action perspective. This would also open up avenues for further improvement of such tool in the operational and functional level of the university so that graduates production process and overall university outcome may also gaze with the lenses of systems view.

\section{Future scope of study and limitation}

The present study is confined to the higher education scenario with special focus on leaders whereas the application of systems thinking is equally important for teachers, staff and students, hence study limits to cover every stakeholder's thinking pattern, which may be taken as the further scope of the investigation. The present study has taken Asian context, therefore, geographical comparison and cultural influence on systems thinking perspectives must be taken as a further effort of empirical studies as 
the cultural background has a strong influence on thinking patterns (Markus \& Kitayama, 1991). The study has involved higher education leaders as participants whereas corporate leaders from manufacturing, service and trading industry may also be taken as a new sample of the investigation. Systems thinking in action can be best investigated in the qualitative approach as behavioural aspects are more nicely studied in qualitative methods.

\section{References}

Ackoff, R. L., \& Warfield, J. N. (1974), "Redesigning the Future: a Systems Approach to Societal Problems." IEEE Transactions on Systems, Man, and Cybernetics. doi:10.1109/TSMC.1977.4309613.

Arnold, R. D., \& Wade, J. P. (2015), "A definition of systems thinking: A systems approach.", In Procedia Computer Science, Vol. 44, pp. 669-678. https://doi.org/10.1016/j.procs.2015.03.050.

Bertalanffy, L. (1968), "General system theory: Essays on its foundation and development", rev. ed. New York: George Braziller.

Behl, D. V., \& Ferreira, S. (2014), "Systems thinking: An analysis of key factors and relationships." In Procedia Computer Science, Vol. 36, pp. 104-109. doi:10.1016/j.procs.2014.09.045

Busayamas Phosai (2016), "Status of Education and Higher Education in Thailand: The Thai education system and the challenges to becoming a successful graduate." Retrieved from iasas.global/wp-content/uploads/2016/08/Thailand_16.pdf

Bellman, R. E., \& Zadeh, L. A. (1970), "Decision-making in a fuzzy environment.”, Management science, Vol. 17, No. 4, pp. B-141.

Cabrera, D., Cabrera, L., Powers, E., Solin, J., \& Kushner, J. (2017), “Applying systems thinking models of organizational design and change in community operational research." European Journal of Operational Research. doi:10.1016/j.ejor.2017.11.006.

Checkland, P. (2000), "Soft Systems Methodology: A Thirty Year Retrospective. Systems Research and Behavioral Science, Vol. 17, pp. 11-58. doi:10.1002/10991743(200011)17:1+<::AID-SRES374>3.0.CO;2-0.

Checkland, P. (1981), "Systems Thinking, Systems Practice. Systems Thinking Systems Practice." doi:10.1016/0143-6228(82)90039-X.

Chen, S.H., Hsieh, C.H., (1998), "Graded mean integration representation of generalized fuzzy number. In: Proceedings of 1998 Sixth Conference on Fuzzy Theory and its Application.", Chinese Fuzzy System Association, Taiwan, pp. 1e6.

Chien-Chang, C., (2012), "Evaluating the quality of airport service using the fuzzy multicriteria decision-making method: a case study of Taiwanese airports.", Expert Syst. Vol. 29, No. 3, pp. 246e260.

Chiadamrong, N. (1999), "An integrated fuzzy multiple criteria decision making method for manufacturing strategies selection." Computer and industrial engineering. Vol. 37, pp.433-436.

Chien, C.J. and H.H. Tsaia. (2000), "Using fuzzy numbers to evaluate perceived service quality.", Fuzzy sets and systems. Vol. 116, pp. 289-300.

Chen, C.T. (2000), "Extensions of the TOPSIS for group decision making under fuzzy environment." Fuzzy Sets Systems. Vol. 114, No. 1, pp. 1-9.

Clarke, S., \& Lehaney, B. (2000),"Mixing methodologies for information systems development and strategy: A higher education case study." Journal of the 
Operational Research Society, Vol, 51, No. 5, pp. 542-556. doi:10.1057/palgrave.jors.2600865

Caputo, F. (2016), "A Focus on Company-stakeholder Relationships in the Light of the Stakeholder Engagement Framework.",In Innovation, Entrepreneurship and Digital Ecosystems, edited by D. Vrontis, Y. Weber, and E. Tsoukatos, pp. 455470. Cyprus: EuroMed Press

Debowski, S., \& Blake, V. (2007), “The collective capacity building of academic leaders: a university model of leadership and learning in context.", International Journal of Learning and Change, Vol. 2, No. 3, pp. 17-31.

Davidz, H. L., \& Nightingale, D. J. (2008),"Enabling systems thinking to accelerate the development of senior systems engineers.",Systems Engineering, Vol. 11, No. 1, pp. 1-14. doi:10.1002/sys.20081.

Davidz, H.L. (2006), "Enabling systems thinking to accelerate the development of sineor systems engineers.","A dissertation submitted to the Engineering Systems Division for the Degree of Doctor of Philisophy in Engineering Systems at Massachusettes Institute of Technology." retrived fromhttps://pdfs.semanticscholar.org/98c1/c08eeed5ee7400ffec8b98fe2cc7a3f 98b6b.pdf

Despres, B. R. (2004), "Systemic thinking and education leadership: Some considerations." International Electronic Journal of Leadership in Learning.

Enrique, H.V. (2004). "Fuzzy qualitative model to evaluate the quality on the web. In: Modeling decisions for artificial intelligence", First international conference. Barcelona,Spain: Springer-Verlag: Berlin Heidelberg, pp.15-27.

Furst-Bowe, J. (2011), "Systems thinking: Critical to quality improvement in higher education." Quality Approaches in Higher Education, Vol. 2, No. 2, pp. 2-5.

Frank, M. (2010), "Assessing the interest for systems engineering positions and other engineering positions' required capacity for engineering systems thinking (CEST)". Systems Engineering, Vol. 13, No. 2, pp. 161-174. doi:10.1002/sys.20140.

Garg, H. (2017), "Some picture fuzzy aggregation operators and their applications to multi-criteria decision-making." Arabian Journal for Science and Engineering, Vol. 42, No. 12, pp. 5275-5290.

Gregory, W. J., \& Midgley, G. (2000), "Planning for disaster: Developing a multi-agency counselling service". Journal of the Operational Research Society, Vol. 51, No. 3, pp. 278-290. https://doi.org/10.1057/palgrave.jors.2600912.

Hutcheson G., \& Sofroniou N. (1999), "The multivariate social scientist: introductory statistics using generalized linear models." London: Sage Publication.

Hill, P. (1971), "Towards a New Philosophy of Management," Gower Press, Epping.

Houston, D., Robertson, T., \& Prebble, T. (2008), "Exploring quality in a university department: Perspectives and meanings." Quality in Higher Education, Vol. 14, No. 3, pp. 209-223.

Hwang, C.L. and K. Yoon.(1981), "Multiple Attribute Decision Making: Methods and Application." New York: Springer-Verlag.

Hsu, H. M., \& Chen, C. T. (1997), "Fuzzy credibility relation method for multiple criteria decision-making problems" Information Sciences, Vol. 96, No. 1-2, pp.79-91.

Ison, R. (1999), "Applying systems thinking to higher education. Systems Research and Behavioral Science", Vol. 16, pp. 107-112. doi:10.1002/(SICI)10991743(199903/04)16:2<107::AID-SRES278>3.0.CO;2-E

Jenkins, D. (2007), "Institutional effectiveness and student success: A study of high- and 
low-impact community colleges. Community College Journal of Research and Practice, Vol. 31, No. 12, pp. 945-962. doi:10.1080/03601270701632057.

Kordova, S. K., \& Frank, M. (2015), "Systems Thinking - Innate or Learned ? Recent Study Findings.", IEEE, pp. 1490-1493. doi:10.1109/IEEM.2015.7385895.

Kapsali, M. (2011), "Systems thinking in innovation project management: A match that works.", International journal of project management, Vol. 29, No. 4, pp. 396-407.

Levin, J. S., Cox, E. M., Cerven, C., \& Haberler, Z. (2010), "The Recipe for Promising Practices in Community Colleges.", Community College Review, Vol. 38, No. 1, pp. 31-58. doi:10.1177/0091552110374505

Lewin, K. (1946), "Action research and minority problems.”, Journal of social issues, Vol. 2, No. 4, pp. 34- 46.

Liang, G. S., \& Wang, M. J. J. (1991), "A fuzzy multi-criteria decision-making method for facility site selection.", The International Journal of Production Research, Vol. 29, No. 11, pp. 2313-2330.

Mathworks.( 2012), Fuzzy logic toolbox user's guide. Natick: The MathWorks, Inc.

Markus, H. R., \& Kitayama, S. (1991). "Culture and the self: Implications for cognition, emotion, and motivation". Psychological Review, Vol. 98, No. 2, pp. 224-253. https://doi.org/10.1037/0033-295X.98.2.224.

McLean, G. N. (2005), "Doing Organization Development in Complex Systems: The Case at a Large U.S. Research, Land-Grant University". Advances in Developing Human Resources, Vol. 7, No. 3, pp. 311-323. doi:10.1177/1523422305277172.

Miller, J. G., (1978), “Living Systems”, McGraw-Hill, New York.

Mitroff, I. I., Mason R. O., (1981), "Creating a Dialectical Social Science: Concepts Methods and Models", Reidel, Dordrecht, London,

Midgley, G., Munlo, I., \& Brown, M. (1998), "The theory and practice of boundary critique: Developing housing services for older people." Journal of the Operational Research Society, Vol. 49, No. 5, pp. 467-478. https://doi.org/10.1057/palgrave.jors.2600531

Mononen, L. (2017),"Systems thinking and its contribution to understanding future designer thinking. In Design for Next : Proceedings of the 12th European Academy of Design Conference (pp. S4529-S4538)". Design Journal, Vol. 20, Suppl. 1. Taylor \& Francis. doi:10.1080/14606925.2017.1352949

Moore, S. M., Dolansky, M. A., Singh, M., Palmieri, P., \& Alemi, F. (2010), "The systems thinking scale." Cleveland: Case Western Reserve University.

Peggy Simcic Brønn \& Carl Brønn (2017), "Systems Thinking: A Method for Reducing Reputation Risk,International Studies of Management \& Organization." Vol. 47, No. 3, pp. 293-305, DOI: 10.1080/00208825.2017.1318024.

Pandey, M. M. (2016), "Evaluating the service quality of airports in Thailand using fuzzy multi- criteria decision making method." Journal of Air Transport Management, 57, 241-249. doi:10.1016/j.jairtraman.2016.08.014.

Pandey, M.M., Singh, D.P., Jayraj, R., Damodaran, K.V., (2018). Evaluating he Success Factors for Development and Sustenance of Low-Cost Regional Airports in India using Fuzzy Multi-Criteria Decision Making Method. Journal of Applied Economic Sciences, Volume XIII, Spring, Vol. 1, No. 5, pp. 89 - 100.

Phosai Busayamas (2016), "Status of Education in Thailand; The Thai Education systems and the challenges to becoming a successful graduate". Retrieved from http://iasas.global/wp-content/uploads/2016/08/Thailand_16.pdf.

Richmond, B. (1997), "The "thinking" in systems thinking: how can we make it easier to master". The Systems Thinker, Vol. 8, No. 2, pp. 1-5. 
Robbins, S. (2006), "Image Slippage: Navigating the Dichotomies of an Academic Identity in a NonAcademic Virtual World.", Education Workshop at the Second Life Community Convention. San Francisco, August 2006.

Ken Robinson (2010), "Bring on learning's revolution", video retrieved from https://www.ted.com/talks/sir_ken_robinson_bring_on_the_revolution\#t268618.

Senge, P. (1995), “On schools as learning organizations: A conversation with Peter Senge.", Educational Leadership (April). Alexandria, VA: Association for Supervision and Curriculum Development.

Singh K., G., \& Kumar, S. (2009), "Role of the Fuzzy System in Psychological Research." Europe's Journal of Psychology, Vol. 2, pp. 123-134. doi:10.1037/e676822011011.

Temel, T. (2005), "A systems approach to malaria control: an institutional perspective", Health policy, Vol. 71, No. 2, pp. 161-180.

Wolstenholme, E. (1993), "Examining of interface of elderly patients from community to hospitals to community care managed by two entities", (National health Service and Personal Social Service). J. Open Res Soc. Vol. 44, No. 9, pp. 925-934.

Zadeh, L. A. (1973), "Outline of a new approach to the analysis of complex systems and decision processes", IEEE Transactions on systems, Man, and Cybernetics, Vol. 1, No. 1, pp. 28-44

Zadeh, L. A. (1975), "The concept of a linguistic variable and its application to approximate reasoning-I", Information sciences, Vol. 8, No. 3, pp. 199-249.

\section{Appendix 1}

1. Items used for mapping the STA in performance level;

Diagnosis and Analysis

- I relate to vision and mission of my university/college to my practice at all level of operations.

- I organize events and meeting to all the stakeholders to know their opinion, ideas and needs.

- I practice with conducting surveys in my university

- I take a decision on the basis of results gained from data analysis.

- I understand and apply the inter-connection and interdependencies between Physical/material systems and Psychological systems interacting in my university.

\section{Modeling}

- I prefer modelling systems and behavioural patterns in my university/department/institute.

- I create the visual mapping with clear boundaries between the academic and non-academic department

- I tend to map the cognitive paradigm of stakeholders involved (Conceptually understanding the mapping of the thinking patterns of stakeholders).

- I tend to model the systems changes for bringing improvement

- I develop a framework for the initiating change in my department/university/institute.

Intervention and Action Plan

- I try to do and act for initiating change.

- I align all the support with the system required to make the change happen.

- I give focus on collaboration among stakeholders

- I often give direction and motivate my staff/fellow members towards the goals.

- I tend to check the feedback in every interval and give immediate control on the deviation.

\section{Review and Learning Phase}

- I often do impact analysis after execution of the project and try to assess the result.

- I try to map the project contribution to the systems and try to map the gap between expected and actual outcome.

- I chart out the mistakes and try to eradicate the consequences if happened.

- I tend to learn the lessons from the failure and validate my perspective.

- I always tend to identify the area of improvement for the next change plan.

2. Items used for mapping the STA in perceived importance level.

All the items in this section are same as indicated in the Analytical Hierarchical Process. 